\title{
Physicians, Patients, and the Electronic Health Record: An Ethnographic Analysis
}

\author{
William Ventres, $M D, M A^{1}$ \\ Sarab Kooienga, FNP ${ }^{2}$ \\ Nancy Vuckovic, $P b D^{3}$ \\ Ryan Marlin, MD, MPH \\ Peggy Nygren, $M A^{2}$ \\ Valerie Stewart, $P b D^{4}$ \\ 'Multnomah County Health Department, \\ Mid-County Health Center, Portland, Ore \\ ${ }^{2}$ Oregon Health and Science University, \\ Portland, Ore \\ ${ }^{3}$ Kaiser Permanente Center for Health \\ Research, Portland, Ore \\ ${ }^{4}$ Providence Health System, Portland, Ore
}

Conflicts of interest: none reported

\section{CORRESPONDING AUTHOR}

William Ventres, MD, MA Multnomah County Health Department Mid-County Health Center 12710 SE Division Street Portland, OR 97236

william.b.ventres@co.multnomah.or.us.

\begin{abstract}
PURPOSE Little is known about the effects of the electronic health record (EHR) on physician-patient encounters. The objectives of this study were to identify the factors that influence the manner by which physicians use the EHR with patients.

METHODS This ethnographic study included 4 qualitative components: 80 hours of participant observation in 4 primary care offices in the Pacific Northwest; individual interviews with 52 patients, 12 office staff members, 23 physicians, and 1 nurse-practitioner; videotaped reviews of 29 clinical encounters; and 5 focusgroup interviews with physicians and computer advocates. The main outcome measures were factors that influence how physicians use the EHR. Researchers qualitatively derived these factors through serial reviews of data.
\end{abstract}

RESULTS This study identified 14 factors that influence how EHRs are used and perceived in medical practice today. These factors were categorized into 4 thematic domains: (1) spatial-effect of the physical presence and location of EHRs on interactions between physicians and patients; (2) relational-perceptions of physicians and patients about the EHR and how those perceptions affected its use; (3) educational-issues of developing physicians' proficiency with and improving patients' understandings about EHR use; and (4) structural-institutional and technological forces that influence how physicians perceived their use of EHR.

CONCLUSIONS This study found that the introduction of EHRs into practice influences multiple cognitive and social dimensions of the clinical encounter. It brings into focus important questions that through further inquiry can determine how to make best use of the EHR to enhance therapeutic relationships.

Ann Fam Med 2006;4:124-131. DOI: 10.1370/afm.425.

\section{INTRODUCTION}

Whe electronic health record (EHR) is a new technology touted as a standard of practice for American medicine in the 21 st century. ${ }^{1,2}$

This technology brings the medical record and health informa-

tion into the examination room through computer hardware and software, patient education materials, and Internet search capabilities. Several authorities endorse the transition to EHRs and promote a technologybased information infrastructure that eliminates handwritten clinical data within 10 years. ${ }^{3,4}$

Numerous authors have discussed the theoretical benefits of computers in clinical practice, ${ }^{1,5-7}$ and differences exist when comparing the use of EHRs with paper charts. ${ }^{78}$ Although these differences have not been found to affect patient satisfaction, ${ }^{9-11}$ little else is known about the effects of this technology on physician-patient encounters.

Studies examining clinical encounters with EHRs suggest that physicians using EHRs preferentially structure interviews around data-gathering demands rather than patients' own narratives. ${ }^{12,13}$ Recent data, however, suggest that this pattern relates more to physician style than to EHR use alone. ${ }^{14}$ Physicians using EHRs also engage in a variety of computer-related 
behaviors that patients find disturbing, ${ }^{15-17}$ as when patients sit idle while their physicians silently perform computational tasks at the computer screen.

The purpose of this work was to explore how EHRs affect the encounters between physicians and their patients. In light of the paucity of published information about the influence of EHRs on the human dimensions of clinical interactions, this qualitative investigation sought to determine those factors that influence the manner by which physicians use the EHR with patients and to provide a framework for considering how physicians might best use the EHR to foster therapeutic relationships with their patients.

\section{METHODS}

Our descriptive study used ethnography as its core research method. Techniques fundamental to this approach include prolonged exposure of the investigators in the study environment, detailed collection of data through field notes and interviews, and extensive review of data from multiple perspectives. ${ }^{18}$

\section{Setting}

We conducted our study in 4 primary care practices in the Pacific Northwest (Table 1). We selected these practices to provide diversity in geographical location, patient populations, and relative experience with the EHR. The study received human subjects' approval from the Institutional Review Board of the Providence Health System of Oregon. Physicians and patients gave written informed consent before entering the study. Non-English-speaking patients were excluded from participation.

\section{Data Collection}

To collect data, we used 4 methods common to qualitative studies ${ }^{19}$ (Table 2). These methods were especially pertinent to this investigation because they allowed us, as researchers, an intense analysis of patient and physician behaviors within examination rooms. Data collection took place concurrently over 2 periods lasting approximately 3 -months each. Funding and methodological considerations, including our interest in providing a longitudinal context to the study, influenced this timing. In all, 2 field researchers gathered data in 4 medical offices from 23 physicians and 1 nursepractitioner, 12 clinic staff members, and 52 patients. Because physicians were overwhelmingly represented in this study, we will refer to the 24 clinical participants as physicians, with the understanding that this group included 1 nurse-practitioner.

Table 1. Summary of Clinic and Participant Characteristics

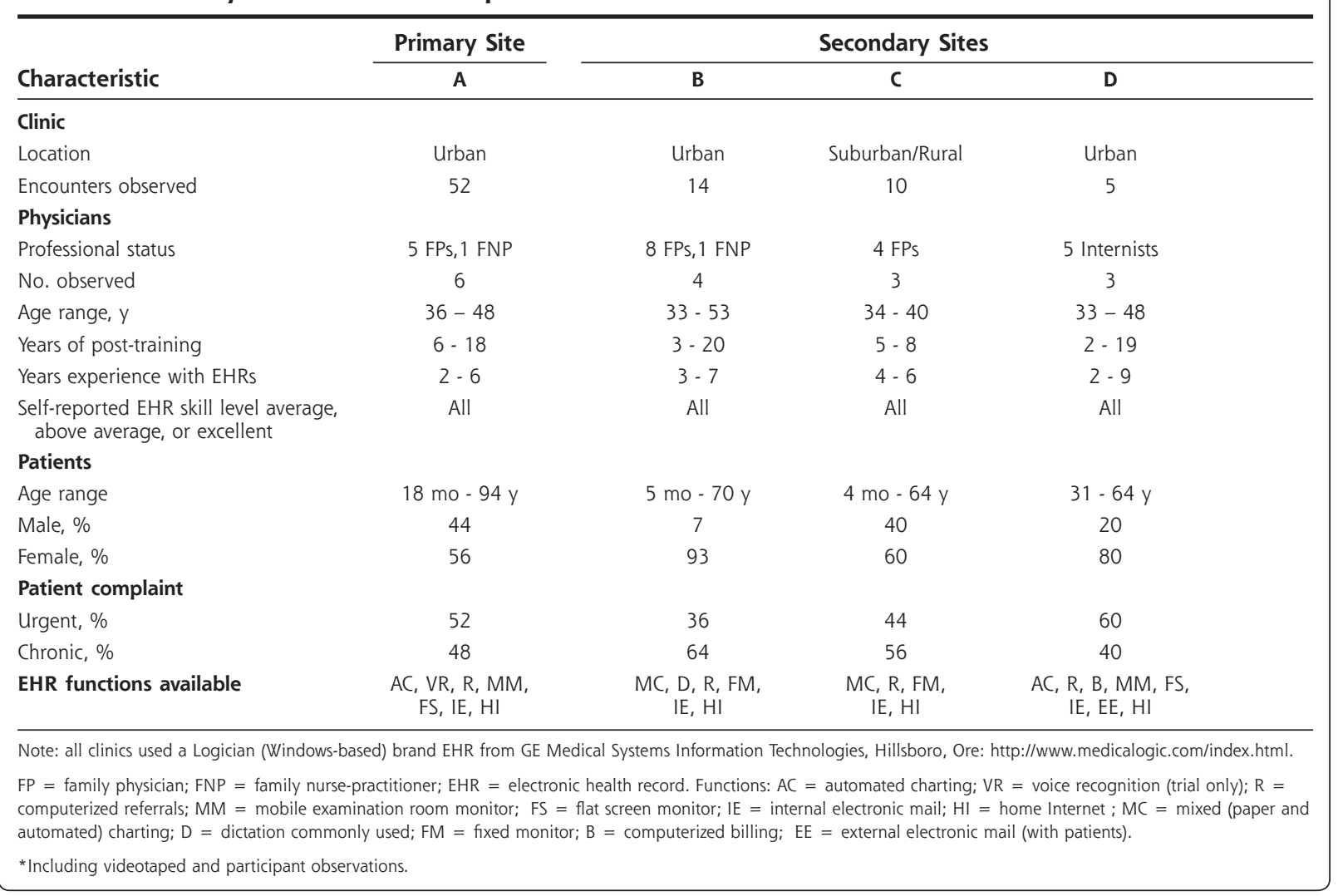




\begin{tabular}{|c|c|c|c|c|c|}
\hline \multirow[b]{2}{*}{ Method } & \multicolumn{2}{|c|}{$\begin{array}{l}\text { Individual Interviews } \\
\text { April-July 2001* } \\
\text { August-October } 2003^{\dagger}\end{array}$} & \multirow{2}{*}{$\begin{array}{l}\text { Videotaped Encounters } \\
\text { August-September } 2003^{\dagger}\end{array}$} & \multirow{2}{*}{$\begin{array}{c}\text { Focus Group Interviews } \\
\text { April-July } 2001^{*} \\
\text { August-October } 2003^{\dagger}\end{array}$} & \multirow{2}{*}{$\begin{array}{l}\text { Participant Observation } \\
\text { April-July 2001 * } \\
\text { August-October } 2003^{\dagger}\end{array}$} \\
\hline & In-Depth & Brief & & & \\
\hline \multicolumn{3}{|l|}{ Participants } & Site $=$ Clinic $\mathrm{A}$ & Physicians $=3(n=15)$ & Offices $=1$ primary, \\
\hline Physicians & 8 & 15 & Total encounters $=29$ & Early advocates $=1(n=6)$ & 3 secondary \\
\hline Patients & 1 & 42 & No. of physicians $=6$ & Resident physicians $=1$ & Clinical encounters $=52$ \\
\hline Office staff & 4 & 5 & Encounters $/$ physician $=4-5$ & $(n=6)$ & \\
\hline $\begin{array}{l}\text { Approximate } \\
\text { duration }\end{array}$ & $1 \mathrm{~h}$ & $10 \mathrm{~min}$ & $\begin{array}{l}\text { Duration = range } 1.5-27.8 \\
\text { min, mean } 16.9 \mathrm{~min}\end{array}$ & Duration $=1 \mathrm{~h}$ & Duration $=80 \mathrm{~h}$ \\
\hline
\end{tabular}

\section{Participant Observation}

For approximately 80 hours, researchers observed interactions relating to the EHR in 1 primary study site and 3 secondary sites. Findings of these observations consisted of descriptions of the offices (including the waiting rooms and main reception areas, the medical assistants' stations, examination rooms, and physician work areas), as well as information garnered while shadowing study participants (including patients, medical assistants, and physicians). During this process participants were also asked open-ended questions to develop insights about how events were experienced and reported. Extensive field notes were collected, including drawings diagramming the positions of physicians and patients relative to the examination room computer.

\section{Interviews}

Researchers conducted 75 individual and 5 focus-group interviews of study participants. Those interviewed represented both purposefully selected professional informants knowledgeable about the use of EHRs and randomly selected physicians and patients who could share perspective on ordinary experiences with the EHR. These open-ended interviews were directed toward understanding informants' perspectives on their experiences with the EHR. Most of the in-depth interviews were audiotaped. Notes were taken to record brief interviews.

\section{Videotaping of Clinical Encounters}

Twenty-nine clinical encounters were videotaped in the primary study site. Patient visits were chosen by convenience sampling, based on a researcher's presence in the office and medical assistants' selection of individual patients based on clinic flow. Physician-patient interactions were observed on a remote screen during each videotaped visit and recorded in writing on a standardized assessment form (Appendix). After each series of videotaped visits, a researcher conducted open-ended interviews with each physician, asking about the impact of the EHRs on physician-patient behavior.

Each physician reviewed 1 videotaped visit deemed by researchers to be most representative of his or her clinical behavior in relation to the EHR. The physicians were asked to reflect in writing about key aspects of the observed visit.

\section{Data Analysis}

The researchers, all with master's-level training in qualitative methods, reviewed and analyzed all information gathered using standard protocols described in Table $3 .{ }^{19}$ Although all the researchers had previous exposure to the use of EHRs, they brought varying methodological and clinical perspectives to the data analysis. These diverse backgrounds allowed for discussion of differing interpretations of what was observed. The researchers used no predefined theoretical perspective or specific set of guidelines to direct their interpretations. Data were collected until the researchers were confident that the observed emerging patterns were valid.

\section{RESULTS}

We identified 14 factors by which EHR use influenced physician-patient interactions. Each represents a synthesis of data collected by all 4 specific data collection methods. We organized these factors into 4 thematic categories, as illustrated in Figure 1. Following an ethnographic tradition, we list both factors and themes, not according to statistical occurrence, but based on a synthesis of information from the various data sources. We encourage readers to view the results as a picture representing a whole phenomenon - that is, a global view of the factors that influence how physicians use the EHR with patients.

\section{Spatial Factors}

These factors related to how the physical presence and location of the EHR influenced the interaction between 


\begin{tabular}{|c|c|c|}
\hline Data Type & Analysis Activity Conducted Concurrently & Process \\
\hline \multicolumn{3}{|c|}{$\begin{array}{l}\text { Audiotaped individual and } \\
\text { focus-group interviews }\end{array}$} \\
\hline Step 1 & Reviewed transcripts and field notes independently & $\begin{array}{l}\text { Emergent factors highlighted } \\
\text { Illustrative quotations recorded }\end{array}$ \\
\hline Step 2 & $\begin{array}{l}\text { Discussed factors and themes jointly } \\
\text { Identified data to confirm or refute interpretations }\end{array}$ & $\begin{array}{l}\text { Interpretations agreed upon by consensus } \\
\text { Themes categorized using iterative process }\end{array}$ \\
\hline \multicolumn{3}{|l|}{ Videotapes } \\
\hline Step 1 & Reviewed videotapes independently & $\begin{array}{l}\text { Noted characteristic practice behaviors } \\
\text { Identified factors and themes }\end{array}$ \\
\hline Step 2 & Reviewed representative videotaped visits jointly & $\begin{array}{l}\text { Shared independent interpretations } \\
\text { Interpretations agreed upon by consensus }\end{array}$ \\
\hline Step 3 & $\begin{array}{l}\text { Reviewed notes and transcripts of the post-videotape } \\
\text { physician interviews and questionnaires }\end{array}$ & $\begin{array}{l}\text { Shared independent interpretations } \\
\text { Interpretations agreed upon by consensus }\end{array}$ \\
\hline \multicolumn{3}{|c|}{$\begin{array}{l}\text { Written notes from fieldwork } \\
\text { and brief interviews }\end{array}$} \\
\hline Step 1 & $\begin{array}{l}\text { Reviewed all notes from observations and } \\
\text { nontranscribed interviews independently }\end{array}$ & Emergent factors highlighted \\
\hline Step 2 & Reviewed notes jointly & $\begin{array}{l}\text { Interpretations agreed upon by consensus } \\
\text { Themes categorized using iterative process }\end{array}$ \\
\hline \multicolumn{3}{|c|}{ Thematic results } \\
\hline Step 1 & $\begin{array}{l}\text { Results reviewed with medical anthropologist in } \\
\text { serial meetings with researchers }\end{array}$ & $\begin{array}{l}\text { Probed layers of meaning about data obtained } \\
\text { Examined consensus decision-making about } \\
\text { interpretations } \\
\text { Explored outlying interpretations }\end{array}$ \\
\hline \multicolumn{3}{|c|}{ Summarized results } \\
\hline Step 1 & Study results reviewed by four key informants & Critiqued results in writing \\
\hline Step 2 & Reviewed critiques & $\begin{array}{l}\text { Written comments reviewed } \\
\text { Results adapted accordingly }\end{array}$ \\
\hline
\end{tabular}

\section{Figure 1. Themes and factors influencing electronic health record (EHR) use} and physician-patient encounters.

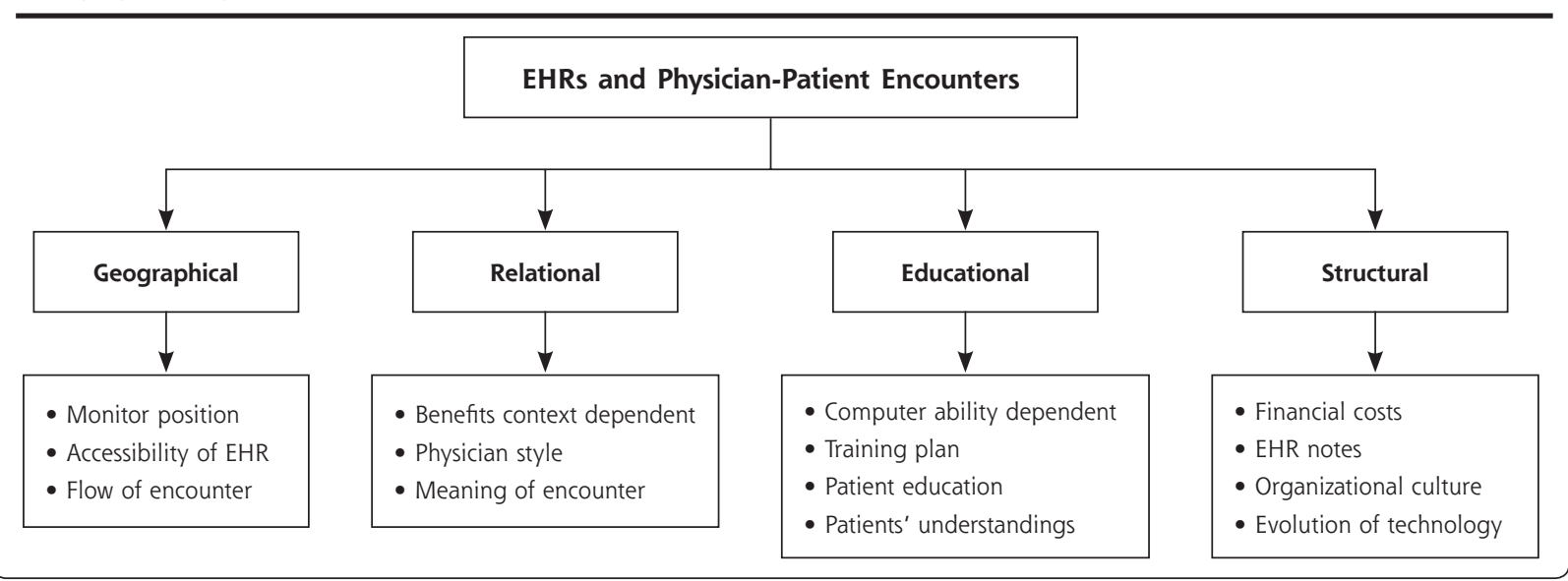

physician and patient. The position of the computer monitor in the examination was clearly the most obvious. Large, fixed monitors located in the corner of the examination room caused consternation among both physicians and patients, whereas flat-screen monitors on mobile arms were universally praised.

The ability to rearrange the position of the monitor changed the dynamic of encounters. It offered physi- cians the opportunity to engage patients in their own medical record.

"I've consciously positioned [the monitor] so patients can see it if they want. It's a conscious statement I make. I like being able to bring the computer into the interaction rather than the computer pulling me away from the interaction." - Physician 1, Clinic A

In practice, this flexibility was infrequently used 
because of a predominance of biomedically focused practice styles and a relative lack of physician interest in fostering patients' involvement. ${ }^{14}$

Accessibility of the EHR gave both physicians and patients a sense of seamless communication over time and location. Field notes showed that study participants were reassured by the convenient availability of computers at numerous locations in the medical office, in the hospital, and at the homes of on-call physicians. This confidence in the EHR was evidenced by the shared belief that at each incremental encounter, current patient information could be added to the medical record in real time.

"The immediacy of electronic access increases the chances that the patients encountering a stranger in their care would get the same experience that they might get from me or my medical assistant knowing them well." - Physician 2, Clinic D

As a result of this sense of immediacy, a concomitant pressure existed for physicians to enter chart notes in the examination room, especially in those offices where dictation was not used. As evidenced in interviews, field notes, and direct observation, physicians were often conflicted between recording medical information in the EHR and giving one-on-one attention to their patients.

"If I feel like my typing is interfering with my relationship with a patient, I stop typing- only then I've got a lot of typing to do later on." - Physician 3, Clinic A

Physicians adopted a variety of techniques to manage this concern. Some typed while patients talked. Most alternated between short blocks of time typing and interviewing. Others reserved data entry to immediately after the encounter, either in examination rooms or returning momentarily to their offices. Still others waited until after office hours, some returning home to complete their charting.

Analysis of videotapes and observation notes showed that the presence of the EHR also had subtle effects on the flow of the encounter. Specifically, unless one reviewed all charts at the beginning of the day-a trait noted in only 1 of 24 physicians - there was little chance for physicians to focus their attention on the patient until after they entered the examination room Once they entered the examination room, physicians most commonly walked straight to the monitor after only a brief greeting. They then opened the EHR and oriented themselves to the patients' previously documented information while their patients either silently sat idle or concurrently related their reasons for the visit. This tendency was not lessened by printed problem and medication lists posted outside the examination room. Some physicians found another way to center themselves with their patients: upon entering the examination room, they greeted their patients, listened to their patients' concerns, and then, after asking tacit permission to review the last visit's notes, moved to the monitor.

\section{Relational Factors}

Relational factors involved how physicians and patients perceived and used the EHR, given the dynamic interplay that occurs between them in the medical encounters. The benefits of charting using the EHR were highly context dependent. Many minor medical problems, such as upper respiratory tract infections and urinary tract infections, had corresponding data entry templates that were loaded into the current visit's record by medical assistants prior to the physician-patient encounter. Physicians had only to point-and-click to complete the history, physical findings, assessment, and plan. Patients expressed that the EHR seemed to fit this kind of to-the-point interaction. The templates, however, did not attend to the patients' narratives or emotional issues, nor did they help manage the complexities of patients with multiple or chronic complaints.

"There are times where it's obvious you're going through a structured way of dealing with a presenting problem. It's click, click, point, and your note is done. Then there are these much more complex, human interactions. It just isn't appropriate to be sitting there typing at the time." - Physician 4, Focus group

"My use of the EHR is limited by the encounter type I'm having. If a patient is coming to me with depression, I leave the computer alone because I think it's kind of cold." - Physician 5, Focus group

Physician style was a major determinant of how the EHR was used in encounters with patients. ${ }^{14}$ Physicians displayed 3 distinct types of practice styles related to EHR use. Informationally-focused physicians commonly positioned themselves at their computer monitors and used computer-guided questioning to focus on problem-oriented details. Physicians with an interpersonal style were led by patient narratives; they either sat or stood away from the computer or faced their patients using the mobility of the computer. Physicians with a managerial style alternated their attention in defined intervals between patients and the computer.

Whether physicians perceived the EHR as important in developing the meaning of the encounter influenced how they used it. Those who saw the EHR as a means for collaboration were more likely to share the screen with their patients than those who used it more narrowly as a medical record. In the one practice where the EHR was seen essentially as an active component of the physician-patient relationship (Clinic D), the sense of importance was institutionalized. Physicians and patients in this clinic saw the EHR as an indispensable 
component of care, a means to communicate electronically, to share in the building of records, and to establish active patient involvement.

"[We use] the 'nothing about me without me philosophy' about information. Saying things like, 'Would you mind if I typed a few notes into your chart? May I show you what I'm doing?' [Asking how we can] use this EHR technology to promote rather than hinder the clinician-patient relationship." - Physician 2, Clinic D

\section{Educational Factors}

Educational factors dealt with developing physicians' proficiency in using EHRs and improving patients' understandings about how the EHR is used in medical encounters. The simple ability to type was noted overwhelmingly as crucial to using the EHR effectively with patients. Other competencies, such as management of Microsoft Windows, searching the Internet, and manipulating a mouse, were considered a necessity for all physicians using EHRs.

"People have different comfort levels with typing. If you're only able to hunt-and-peck or you've got to look [at the keyboard], you can't [use the EHR] effectively." - Nurse-practitioner, Clinic A

There was much discussion about teaching medical students and residents how to use the EHR in their interactions with patients. Resident physicians in a focus group expressed confusion and anxiety about how to develop their personal communication style with patients at the same time they were expected to chart using EHRs. They believed it was difficult, if not impossible, to learn both at the same time.

Physician educators interviewed individually and in focus groups disagreed about when and how trainees should be introduced to the EHR. Consensus belief was that the EHR should be incorporated in a broader educational context.

"The question in [training] is how to provide quality care. There are a lot of different components [involved]; some are electronic, others not. The EHR is but one part of a larger system." - Physician 6, Clinic D

Patient education was another commonly noted factor, one which revealed a large gap between the potential and the reality of the EHR. Physicians eagerly described the many functions of the EHR, such as electronic communication of laboratory results and advanced searches on the Internet, yet these functions were rarely used in practice (except in Clinic D). Simple data graphing on examination room monitors and printing of educational handouts were the extent of day-to-day clinical work.

Patients were uninformed as to how the EHR was used in their medical care. Although their fears and doubts were common, these feelings were generally unexpressed to their physicians. Patient concerns that were recorded in field notes focused on what would happen if the server went down, whether the information in the EHR was safe from computer hacking, and whether the government or an insurance provider would be able to access records without permission. The patients' comfort with computers influenced their beliefs and concerns.

\section{Structural Factors}

Structural factors concerned institutional and technological forces that influenced how physicians perceived their use of EHR. Monetary costs played a prominent part, especially regarding the question of whether to type or dictate office visit notes into the EHR. Financial commitments to the EHR are considerable, and typing was seen as the only way to limit further expenditures.

Consensus opinion was that EHR notes were concise but lacked the depth and intricacy of narrated notes. There was a subtle cookie-cutter effect to EHRgenerated notes. Study participants observed that, as a result of relying on templates and quick-text features, EHR notes all started looking the same. Some worried about practicing cookbook medicine with the EHR; others reframed this concern:

"The algorithmic part of medicine feeds into the resistance against the EHR. From my perspective, that's a huge benefit of the EHR with patient interaction. I can say, 'Here we have all these protocols set up. Let's pull them up.'" - Physician 7, Focus group

The organizational culture of each clinic affected the implementation and use of the EHR. Each clinic had both enthusiastic supporters and skeptical adopters of the EHR, and the clinics as a whole displayed various degrees of acceptance. These differences were evident in the frustrations individual physicians or practice groups expressed about the EHR. These feelings carried over to clinical interactions, with some physicians quick to remark about their dissatisfactions in front of patients.

All of these factors were seen in the context of evolution of a newly introduced technology. After up to 6 years of daily use, the EHR was considered to be in embryonic stages of development. Physicians and patients were still adapting to its presence as well as its continuing technical updates.

"There's a learning curve. That [the EHR] is so flexible and multifaceted is one of its benefits and one of its huge weaknesses. There are all these things I know I can do so much smarter and better, but I never do. I learn a way to do something and then I do it again and again. I am significantly underutilizing [the EHR]." - Physician 1, Clinic A 


\section{DISCUSSION}

Many mistakenly see the EHR as an updated version of the paper chart, ${ }^{20}$ but behind the superficial resemblance of tabs, notes, and flow sheets is a complicated system of functions (and, correspondingly, of human notions) that play into its application in the medical setting. Seen from the perspective of examination room encounters between physicians and patients, the EHR becomes much like a third party to a conversation. As can be inferred from the results of this study, the EHR has its own separate identity in the encounter, and both physicians and patients project their perceptions onto this identity. They pattern their behaviors accordingly as they go about the shared work of medical care. Given the results of this study and other recent reports assessing the influence of EHRs on the office environment and clinical outcomes, ${ }^{21-23}$ it would be a grave mistake to believe that the effects of EHRs will be automatically and universally positive. The introduction of EHRs into widespread practice - a process envisioned by both the Future of Family Medicine and Institute of Medicine and already well underway ${ }^{2,3}$ — will influence multiple cognitive and social dimensions of the clinical encounter, producing both intended and unintended consequences This ethnography is one of the first steps in identifying the range and importance of these dimensions.

This study identifies numerous factors that shape how EHRs are perceived and used in medical practice today. It suggests that these factors shape the development and sustenance of physician-patient relationships while they influence the implementation of EHRs. These factors demand thoughtful consideration as the use of the EHR proliferates, not only to forestall problems but to maximize the effectiveness of this burgeoning medical technology.

\section{Limitations}

This ethnographic study was conducted in 4 primary care offices. Although the practices displayed a widely diverse behaviors and attitudes, they might not represent the full breadth of behaviors and attitudes that exist related to EHR use. The inclusion of non-Englishspeaking patients may have added new dimensions to the results. All the participants in the study used the same EHR software product. Even though this system compares favorably with other products on the market,24 the characteristics of other EHR systems might have generated different responses from participants. Methodologically, audiotaping all interviews would have added the descriptive power of patients' quoted statements. Also, including relevant patient chart notes may have expanded our insights into the relation between communication between physicians and patients and resultant EHR text.

\section{Table 4. Example Questions Generated by This Study}

Can EHR software be designed to facilitate communication between physicians and patients?

What resources are available to help physicians best integrate this technology into their style of patient care as they transition to the use of the EHR?

Are there examples of best practices-standard procedures or phrases - that physicians can use to assist patients as they are introduced to the EHR?

When and how should medical educators introduce the EHR to students and residents, especially given the current emphasis on training patient-centered interviewing skills?

What responsibilities do vendors or health care systems have to train physicians about the relational aspects of the EHR?

$\mathrm{EHR}=$ electronic health record

This qualitative study has brought into focus several previously undocumented factors that influence the role EHRs have on encounters between physicians and patients. We found that spatial, relational, educational, and structural factors play an important part in how this technology is used in medical encounters. Further attention to these factors and the questions raised by this investigation (Table 4) can facilitate integration of the EHR into medical practice and foster use of the EHR to enhance therapeutic relationships.

To read or post commentaries in response to this article, see it online at http://www.annfammed.org/cgi/content/full/4/2/124.

Key words: Ambulatory care; family practice; physician-patient relations; medical records systems, computerized; methods: qualitative; practice-based research; medical decision making, computer assisted; medical informatics

Submitted May 16, 2005; submitted, revised, August 19, 2005; accepted August 25, 2005.

Preliminary results of this study were presented at the Society of Teachers of Family Medicine 35th Annual Spring Conference, San Francisco, Calif, April 28, 2002.

Funding support: This study was funded by the Joint AAFP/F-AAFP Grant Awards Program (American Academy of Family Physicians) and the Center for Outcomes Research and Education (Providence Health System of Oregon).

\section{REFERENCES}

1. Bodenheimer T, Grumbach K. Electronic technology: a spark to revitalize primary care? JAMA. 2003;290:259-264.

2. Martin JC, Avant RF, Bowman MA, et al. The future of family medicine: a collaborative project of the family medicine community. Ann Fam Med. 2004;2 Suppl 1:S3-32.

3. Institute of Medicine. The Computer-Based Patient Record: An Essential Technology for Health Care. Washington, DC: National Academy Press; 2002.

4. Frist WH. Shattuck Lecture: health care in the 21 st century. N Engl J Med. 2005;352:267-272. 
5. Hersh WR. Medical informatics: improving health care through information. JAMA. 2002;288:1955-1958.

6. Bates DW, Ebell M, Gotlieb E, Zapp J, Mullins HC. A proposal for electronic medical records in U.S. primary care. J Am Med Inform Assoc. 2003;10:1-10.

7. Mitchell E, Sullivan F. A descriptive feast but an evaluative famine: systematic review of published articles on primary care computing during 1980-97. BMJ. 2001;322:279-282.

8. Hippisley-Cox J, Pringle M, Cater R, et al. The electronic patient record in primary care--regression or progression? A cross sectional study. BMJ. 2003;326:1439-1443.

9. Garrison GM, Bernard ME, Rasmussen NH. 21st-century health care: the effect of computer use by physicians on patient satisfaction at a family medicine clinic. Fam Med. 2002;34:362-368.

10. Hsu J, Huang J, Fung V, et al. Health information technology and physician-patient interactions: impact of computers on communication during outpatient primary care visits. J Am Med Inform Assoc. 2005; 12:474-480.

11. Johnson KB, Serwint JR, Fagan LM, Thompson RE, Wilson MH. Computer-based documentation: effect on parent and physician satisfaction during a pediatric health maintenance encounter. Arch Pediatr Adolesc Med. 2005; 159:250-254.

12. Patel VL, Arocha JF, Kushniruk AW. Patients' and physicians' understanding of health and biomedical concepts: relationship to the design of EMR systems. J Biomed Inform. 2002;35:8-16.

13. Makoul G, Curry RH, Tang PC. The use of electronic medical records: communication patterns in outpatient encounters. J Am Med Inform Assoc. 2001;8:610-615.
14. Ventres W, Kooienga S, Marlin R, Vuckovic N, Stewart V. Clinician style and examination room computers: a video ethnography. Fam Med. 2005;37:276-281.

15. Als AB. The desk-top computer as a magic box: patterns of behaviour connected with the desk-top computer; GPs' and patients' perceptions. Fam Pract. 1997;14:17-23.

16. Warshawsky SS, Pliskin JS, Urkin J, et al. Physician use of a computerized medical record system during the patient encounter: a descriptive study. Comput Methods Programs Biomed. 1994;43:269-273.

17. Greatbatch D, Heath C, Campion P, Luff P. How do desk-top computers affect the doctor-patient interaction? Fam Pract. 1995;12:32-36.

18. Ventres W/B, Frankel RM. Ethnography: a stepwise approach for primary care researchers. Fam Med. 1996;28:52-56.

19. Crabtree BF, Miller WL. Doing Qualitative Research. 2nd ed. Newbury Park, Calif: Sage Publications; 1999.

20. Berg M. Medical work and the computer-based patient record: a sociological perspective. Methods Inf Med. 1998;37:294-301.

21. O'Connor PJ, Crain AL, Rush WA, et al. Impact of an electronic medical record on diabetes quality of care. Ann Fam Med. 2005;3:300-306

22. Crosson JC, Stroebel C, Scott JG, Stello B, Crabtree BF. Implementing an electronic medical record in a family medicine practice: communication, decision making, and conflict. Ann Fam Med. 2005;3:307-311.

23. Baron RJ, Fabens EL, Schiffman M, Wolf E. Electronic health records: just around the corner? Or over the cliff? Ann Intern Med. 2005; $143: 222-226$

24. Rehm S, Kraft S. Electronic medical records: the FPM vendor survey. Fam Pract Manag. 2001;8:45-54.

\section{Appendix. Assessment Instrument for Videotaped Encounters}

\begin{tabular}{|l|l|l|}
\hline Visit Section & $\begin{array}{c}\text { Computerl } \\
\text { No Computer }\end{array}$ & Comments \\
\hline Introduction & & \\
\hline Orientation & & \\
\hline Subjective & & \\
\hline Diagnostic thinking & & \\
\hline Prescriptions/plans & & \\
\hline
\end{tabular}

Impressions 